\title{
EEG STUDY OF THE EFFECT OF VIRTUAL REALITY
}

\author{
aPAVEL ROSENLACHER, ${ }^{b}$ MICHAL TOMČÍK, 'MATĚJ \\ BRŮNA
}

Faculty of economic study, University of Finance and Administration, Estonská 500, 101 00, Prague 10, Czech Republic

email: ${ }^{a}$ pavel.rosenlacher@vsfs.cz, ${ }^{b} 14263 @ m a i l . v s f s . c z$, cmatej.bruna@vsfs.cz

Authors acknowledge the support of Research project IGA VŠFS Prague No. 7429/2018/05 - „Consumer's Perceptual Strategies from the Perspective of neuromarketing" funded by the University of Finance and Administration, Prague. University of Finance and Administration, Prague.

Abstract: This study examines the effect of virtual reality on the human brain in terms of how much virtual reality is capable of replacing real-world experiences and affect the human brain. The focus of the study is on the area of neuromarketing where the purpose of our own investigation is to determine the effect of a $360^{\circ}$ advertising spot using a neuromarketing approach. The main objective of our own research is to find out through the EEG brain the effectiveness of advertising spot presented using virtual reality.

Keywords: neuromarketing, electroencephalography, virtual reality, spot advertising, marketing communication, efficiency.

\section{Introduction}

The area of digital technology is constantly evolving and new applications of various technologies are found every day [1]. One of them is a virtual reality technology that gradually finds wider application, although initial efforts to implement it can be observed in the second half of the 20th century [2]. The popularization of virtual reality goes hand in hand with the ongoing affordability of these devices. The consumer at home can afford virtual reality for hundreds of crowns - from the cheapest virtual glasses for smart mobile phones to more sophisticated systems with high quality and content that require a lot of computing power. Virtual reality appears in many areas. The most popular is the gaming industry, but it can also be found in the field of marketing or human resources and the recruitment of new employees into companies.

In connection with the above, the question arises as to how this virtual reality affects the human brain from the point of view of the quality of mediating reality, or the extent to which it can replace reality. Based on this, the aim of this study was to: Identify using the EEG the effectiveness of the performance of a commercial spot presented using virtual reality. For this purpose, a neuromarketing approach to data collection will be used to find out the effect of virtual reality on the human brain, or the level of attention and intensity of emotions experienced.

\section{Neuromarketing}

The Neuromarketing Approach to Primary Data Collection will be used in the own survey methodology. Neuromarketing is a relatively new approach. The combination of neuro and marketing suggests a combination of two areas of neuroscience and marketing. The concept of neuromarketing began to appear in 2002 [3]. Neuromarketing is a relatively new domain of applied marketing research that studies cognitive and affective customer responses to marketing incentives [4]. In addition to neuromarketing, it is useful to mention the term neuroeconomics, which is a multidisciplinary discipline aiming at the neural level to understand human decision making in the economic environment. Researchers explore processes in the brain in situations where people decide, evaluate options, choose preferences [5]. Neuromarketing combines knowledge from neuropsychology, cognitive psychology and neuroscience with the environment of marketing [6]. In summary, neuromarketing can be understood as linking the application of biomedical technology and marketing research [7].

The neuromarketing methods are used to investigate anatomical and physiological functions and behavioural analysis. Most of these methods have their origins in the medical field. It is very often the monitoring of cardiac activity, for example by means of electrocardiography (ECG), skin-galvanic reflex (GSR), eye tracking, or monitoring brain activity by the electroencephalography (EEG) method used in this study to collect primary data [8].

The EEG method can show brain activity in certain mental states such as alertness or drowsiness. Electroencephalography (EEG) is used to detect bioelectric activity of the brain. This activity is shown as form of brain wave, each of which has its own frequency and course reported in Hertz $(\mathrm{Hz})$. Each type of brain wave corresponds to a specific behaviour of humans, gamma waves are related with significant emotional experiences. BETA brain waves associate with thinking, mental activity and considerable effort to focus on the challenge. Brain waves called SMR (sensorimotor) have a relationship to the physical motor, the movements or skills of humans [9]

Although there are a number of other methods to monitor brain activity, such as functional magnetic resonance imaging (fMRI), there are some advantages or disadvantages for each method. The advantage is that nowadays there are portable EEG devices, so collecting primary data may not necessarily be limited to laboratory conditions or only to medical facilities where these methods are commonly used. At the same time, EEG data collection is significantly more cost-effective than functional magnetic resonance imaging [8]. This brings many benefits, since it is possible to study brain activity when observed in a natural environment.

\section{Methodology of its own investigation}

Based on the goal, a survey was carried out using the EEG to test the effectiveness of a advertising spot presented by virtual reality. Following the goal set, to the selected respondents with VR headset an advertising spot was presented, while they were connected to the EEG device to measure the electrical activity of the brain. The survey also includes a control group of respondents who watched the same advertising spot on mobile phone without VR headset. The survey is also complemented by a semi-structured interview.

During the survey, the Teekanne tea spot was presented to the respondents. This spot was chosen because of its format, which is the $360^{\circ}$ video allowing a full-featured presentation through virtual reality. At the same time, it is a promotion of a product that is gender-neutral, and the respondents' gender should not influence the results than if a commercial spot promoting perfume or clothing was chosen. The ad was played using the Youtube portal, which allows uploading and then playing back videos of this format. The content of the advertising spot was the preparation of tea, its pouring into a cup and then shots into a tranquil oriental garden. It is important to note that video content must be conceived in accordance with the video format that allows virtual reality. The above-mentioned video format allows the viewer to move around 360 degrees, which is achieved by moving with VR headset placed on the head. For the control group of respondents, which is described in the next part of this article, the movement of a mobile phone while watching an ad spot replaces VR headset.

Within the survey, respondents were divided into two groups. The first group watched the commercial spot using the headset (glasses) for the virtual reality of the TBW brand with the VR BOX VR-X2. The iPhone SE mobile phone (4-inch screen size) on which the ad spot was played was placed in to this headset. Using a mobile phone accelerometer to detect the orientation of the phone, respondents could look at the $360^{\circ}$ spot through head movements. The goal is to make sure that the respondent immerses in the video and that it brings the illusion of reality. The quality of this experience depends on the technology used. VR headset, which was used, is both financial and hardware 
unpretentious option for simply trying out virtual reality. In the survey, a second, control group of respondents was set up to watch the same spot without using the headset. Respondents from control group watched spot only on the screen of the iPhone SE mobile phone.

Since this was an experimental survey, a sample of respondents comprised of 20 people, divided evenly into two groups - the group that the ad spot was presented with glasses to the virtual reality (headset) and the control group, which was spotted only by the mobile phone. The number of respondents in each group was 10 persons. The selection of respondents took place on the basis of volunteering from bachelor students of the University of Finance and Administration in Most, with an age limit of 18-30 years, given that this younger generation may be more inclined towards digital technologies.

The data collection took place in a quiet, undisturbed room, which was free of external influences such as noise in the corridor etc. The measuring technique was placed in the room behind the respondent's back so that the administrator did not disturb and did not influence respondent during the data collection. Respondents were invited to the room individually, and the time schedule for their invitation was tailored so that they did not meet in the room and could not pass on knowledge from the data collection, which would disrupt the standardization of conditions. Respondents from the first group, who watched the spot with VR headset, were given the Philips headphones before they began collecting data, ensuring a better understanding of audience information from the spot.

After the respondent was seated in the room, the EEG measuring electrodes were placed. In the case of this investigation, the 1020 EEG electrodes were placed at point Fz. The ground electrode was placed on the respondent's left ear or point A1 according to standard 10-20. Nexus-10 was used to retrieve the data, including the BioTrace + software, used to record, display measured data, and to analyse it. This program allows you to select values for specific respondents and export the measured data to the "txt" text format. Data are subsequently processed in the analytical software. EEG monitored the following brain waves: SMR, beta and gamma. Beta waves are typically in the range of $14-30 \mathrm{~Hz}$ and are related to concentration, logicalanalytical thinking. Gamma waves have a frequency of $30 \mathrm{~Hz}$ or more and are associated with emotions and more stressful situations [10]. Using this method, there was a difference in the level of attention and emotion when watching the selected commercial spot compared to the resting state. The resulting values were further compared between the two groups of respondents.

Before the presenting of the selected advertising spot itself, it was necessary to record the values of so-called resting state of the respondents against whom the measured data were compared when watching an advertising spot. Certain calming of respondents (particularly certain stress from EEG measurements) was achieved by a video presentation containing a time lapse record of the blue sky and moving clouds. This is a peaceful shot that is neutral and should not cause significant emotional responses. The footage of this video was 35 seconds. The advertising spot was then presented to the respondents, this process is described in more detail in the previous paragraphs of this article.

When analysing the data, the values of the degree of attention and emotional reactions and their difference were compared to the resting state. The degree of attention was determined by the merging of brain waves SMR and beta, emotional responses were determined based on brain waves of gamma. To determine the extent to which virtual reality influence the level of attention and emotion, the resting state of the respondents (based on a 35second spot with the sky) is compared with the results measured during the presentation of the advertising spot. This makes it possible to determine how much the percentage of attention or emotional responses has changed when watching an ad spot compared to the rest of the respondents. Based on the collected data, the average value of attention and emotional response of respondents who watched the spot using the headset and using a mobile phone was determined by adjusting the data. The resulting data is summarized in Table 1 below.

The survey was further complemented by a post-test in the form of semi-structured personal interviewing, which aimed to find additional data, especially subjective assessments. The form of personal interview was chosen in relation to the type of inquiry, as it allows interviewer to react to the respondent and to obtain deeper information [11]. The interview consisted of eleven questions related to how subjectively respondents rate the presented spot. In addition, the questions concerned virtual reality and the idea of its potential use in marketing were contained. Among other things, the experiences of respondents with virtual reality and their opinion on technologies of this type were surveyed. Specifically, these were questions about whether the respondent would be interested in the advertising presented in this way or whether the virtual reality has a future in marketing. The interview consisted of 9 open questions and 2 questions that included a five- and ten-point numerical rating scale.

\section{Results}

As mentioned above, the BioTrace + software was used to evaluate the data, from which the data was exported to a text format for subsequent statistical processing in Excel after the reduction of artefacts. From these numerical values, a summary table representing the measured data for both groups of respondents - for respondents following the spot using VR headset (row 2 in the table) and the control group watching the spot without glasses using the mobile phone - was created (row 3 in the table).

Tab. 1: Summary data from brain EEG measurements

\begin{tabular}{|c|c|c|}
\hline & Attention (\%) & Emotions (\%) \\
\hline VR headset & 106,60 & 94,80 \\
\hline Mobile phone & 74,25 & 70,25 \\
\hline
\end{tabular}

The table above shows the difference in respondents' attention and emotions when viewing the presented advertising spot compared to the resting state measured at the beginning when watching a time lapse image of the sky. Resting state has a default value of $0 \%$ and represents a landmark that can be used to define an increase in the respondent's attention when watching an ad spot. It can be seen from the table that respondents who had VR headset during the measurements had developed a higher level of attention than the other group. Specifically, the difference is $32.35 \%$.

In the next column, there is a difference in the degree of emotion compared to the resting state. For emotions, the difference between test groups was $24.55 \%$. In this case, the group with the head of virtual reality has also reached higher values compared to the control group.

EEG findings show that respondents are more attracted when watching an advertising spot with VR head, as evidenced by the increased attention and emotional responses experienced by the respondents. The results can be attributed to the fact that virtual reality allows the viewer to immerse into the game and to convey to him a deeper, more credible experience, which is also reflected in the brain activity. On the basis of the values found, the human brain can perceive virtual reality suggestions as a certain copy of it, but it has a rather strong effect compared to the effect of a mobile phone. At the same time, another factor may be the fact that virtual reality technology is currently not widespread among the public (see Figure 1) and so the respondents perceive VR as something new and unknown.

Part of the survey methodology was also a semi-structured interview that took place immediately after the end of the EEG data collection. In the interview, the respondents were first asked 
about the current verbal rating of the ad viewed. Respondents from the group with VR headset rated the commercials more often as an entirely positive ( $90 \%$ of total respondents). In the second, the control group, the respondents rated the advertising spot as mostly positive or mixed ( $40 \%$ rated it positively).

Whether this will be a positive experience also depends on a certain amount of comfort when watching the ad. Respondents who watched the spot using the headset were asked if the experience was pleasant. For this purpose, a five-point numerical rating scale was used, in which the value 1 was "very pleasant" and the value of 5 was "very unpleasant". This question was considered only for the group with VR headset so only 10 respondents answered this question. Values marked on the scale were processed by all 10 respondents using descriptive statistics, the results of which are summarized in table 2 below.

Tab. 2: Evaluation of the five-point rating scale

\begin{tabular}{|c|c|}
\hline Diameter & 2,4 \\
\hline Median & 2,0 \\
\hline Standard deviation & 0,5 \\
\hline
\end{tabular}

The average rating of the respondents was 2.4, which represents the approximate centre of the scale and therefore the rating that is not entirely positive but not entirely negative. After additional queries, it was found that most respondents were rather neutral about this form of spot tracking. It is important to mention here that the quality of the experience also depends on the technology used. The better source content and better technology, the better the experience of virtual reality. The vast majority of respondents claim that virtual reality has a future and potential in marketing. Specifically, it is $80 \%$ of the respondents. The remaining $20 \%$ of those who responded negatively added their comment that they could not imagine a specific use in marketing and also mentioned the limits of this technology at the moment.

Part of the interview was also the question of subjective evaluation of an advertising spot presented using virtual reality. For this purpose, the 10-point Likert scale was used, where the respondent assessed the claim using the scale: "the presentation spot was very interesting". Within the Likert scale used, the value of 1 was "disagree" and the value of 10 represented the "agree" rating. The results are processed for both groups of respondents, using descriptive statistics.

Tab. 3: Evaluation of the 10-point Likert scale

\begin{tabular}{|c|c|c|}
\hline & VR headset & Mobile phone \\
\hline Diameter & 8,6 & 5,8 \\
\hline Median & 9,0 & 7,5 \\
\hline Standard deviation & 1,4 & 1,9 \\
\hline
\end{tabular}

It's clear from the table that the ad was more appealing to the respondents who watched her with virtual reality glasses. This was followed by another question that explored the reasons for such an assessment, with the result that respondents with glasses most often cited the creativity and originality of advertising spot, which may also be influenced by virtual reality technology. Another part of the interview was a question addressed to the respondents' experience with virtual reality technology. In this case, it was again an open question. According to Figure 1 below, it is clear that over half of respondents (60\% in total) have no experience with virtual reality. Based on an additional comment, these respondents have heard only briefly about this technology. This survey was the first direct experience of virtual reality for respondents. A further $30 \%$ of respondents tried virtual reality at least once, and only $10 \%$ had more experiences with virtual reality, such as PlayStation VR. Interestingly, no respondent noticed virtual reality in marketing. However, it is possible to discuss that some people who encounter virtual reality do not even realize that - for example there are some mobile applications that allow virtual reality but are not fully exploited by the user.
Fig. 1: Evaluation of question 8 of the interview

Experiences of respondents with VR

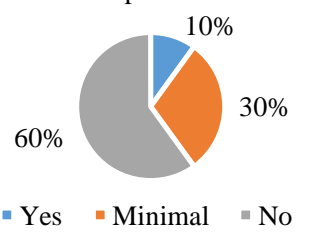

\section{Conclusion}

The survey shows that viewing advertising through virtual reality increases the level of attention and emotion compared to watching only through the mobile phone screen. From the point of view of the possibilities of virtual reality in marketing, based on the results, it offers a tool that can convey deeper action and better transmission of the message. According to other results, it was found that advertising presented using virtual reality is mostly positively perceived. Interestingly, the majority of respondents did not encounter virtual reality, and this fact shows little public awareness of the area. Virtual reality is currently expanding mainly in the gaming industry, and it penetrates marketing rather slowly, although there are already marketing uses, for example in the real estate market. Most respondents, however, think that virtual reality has a future in marketing. This is conditioned, in particular, by technological advancement and accessibility, where high-quality virtual reality headsets are very costly and demand high-performance hardware.

\section{Literature:}

1. MILKOVÁ, Eva. Multimedia applications as an effective complement to the educational proces. In Advanced educational technologies (EDUTE 10). Book Series: Recent Advances in Computer Engineering, 2010. pp. 62-67. ISBN 978-960-474186-1, ISSN 1790-5109.

2. CARMIGNIANI, Julie et al. Augmented reality technologies, systems and applications. Multimedia Tools and Applications [online]. 2011, vol. 51, no. 1, pp. 341-377. ISSN 13807501.

3. MORIN, Christophe. Neuromarketing: The New Science of Consumer Behavior. In Society [online]. 2011, vol. 48, no. 2, pp. 131-135. ISSN 01472011.

4. BREMER, Józef. CZYM JEST NEUROMARKETING?/ WHAT IS NEUROMARKETING?. Communication Today [online]. 2013, vol. 4, no. 1, pp. 18-35. ISSN 1338130X.

5. CHRISTIANSEN, Bryan. Neuroeconomics and the DecisionMaking Process. Hershey, Pennsylvania: IGI Global, 2016. ISBN 14-666-9990-6.

6. VYSEKALOVÁ, Jitka. Chování zákazníka: jak odkrýt tajemství "černé skřiňky". Praha: Grada Publishing, 2011. ISBN 978-80-247-3528-3.

7. ROSENLACHER, Pavel. Využití zdravotnické techniky v neuromarketingu. In Ekonomika a management ve zdravotnictví. $3^{\text {rd }}$ edition. Praha: ČVUT, FBMI, 2013. pp. 82 - 86. ISBN 97880-01-05277-8.

8. ZURAWICKI, Leon. Neuromarketing: exploring the brain of the consumer. London: Springer, 2010. ISBN 978-3-540-77828-4. 9. HRONOVÁ, Štěpánka and Pavel ROSENLACHER. A Crossdisciplinary Approach: ESP Instruction and Implementation of Neuromarketing Methods as Curriculum Innovation. In DisCo: From analog education to digital education - 10th conference reader. Praha: Centrum pro studium vysokého školství, 2015. pp. 179-186, 8 p. ISBN 978-80-86302-47-8.

10. SINGH, Pushpendra et al. Fourier-Based Feature Extraction for Classification of EEG Signals Using EEG Rhythms. Circuits, Systems, and Signal Processing [online]. 2016, vol. 35, no. 10, pp. 3700-3715. ISSN 0278081X.

11. KOZEL, Roman. Moderní marketingový výzkum. Praha: Grada Publishing, 2006. ISBN 80-247-0966-X.

\section{Primary Paper Section: A}

Secondary Paper Section: AN, AH, IN 